\title{
Home Office em uma multinacional de tecnologia da informação
}

\author{
RESUMO
}

Evandro Lucas Pereira evandroluc@hotmail.com

Universidade Federal de São Carlos (UFSCar), São Carlos, São Paulo, Brasil

\section{Alessandra Rachid}

arachid@ufscar.br

Universidade Federal de São Carlos (UFSCar), São Carlos, São Paulo, Brasil
Este texto analisa o trabalho em home office, suas vantagens e desvantagens a partir da percepção dos trabalhadores. Para isso, foi realizada uma pesquisa em uma empresa multinacional de tecnologia da informação ( $\mathrm{TI})$, a partir de um questionário respondido por 52 funcionários, entrevistas com 15 destes respondentes, observação destes quando íam à empresa e de uma entrevista com um diretor da área de vendas. A percepção dos funcionários confirma muitas das vantagens apontadas pela literatura, como menores custos, maior produtividade, maior conforto e liberdade, entre outros. Também foi possível confirmar aspectos negativos, como a extensão da jornada de trabalho e o isolamento. Os aspectos em relação aos quais houve divergências em relação à literatura foi a vantagem de fugir do jogo político da empresa e a facilidade para realizar tarefas domésticas.

PALAVRAS-CHAVE: Organização do trabalho. Teletrabalho. Home-office. Tecnologia da informação. 


\section{INTRODUÇÃO}

Este texto analisa o trabalho no regime home office, com uso de dispositivos móveis conectados à internet. Para tal, foi realizado um estudo de caso em uma multinacional de tecnologia da informação (TI), a fim de levantar as percepções dos trabalhadores em relação a benefícios e prejuízos do home office.

Dias (2000) realizou uma pesquisa envolvendo 43 empresas do Brasil e os gerentes entrevistados afirmaram que usam a TI porque ela aumenta a qualidade de seu trabalho, facilita a execução de tarefas e melhora sua produtividade. Uma das consequências do aumento do uso da TI é a maior facilidade para realizar o teletrabalho ou home office, que envolve qualquer forma de trabalho por meio de TI fora da sede da organização (TREMBLAY, 2002).

Para Kanter (2010), o home office, além de reduzir o congestionamento e a poluição nas ruas, é capaz de melhorar a relação dos trabalhadores com suas famílias e com o próprio trabalho, com níveis reduzidos de estresse e má alimentação. Segundo Tietze (2005), no entanto, foram percebidos efeitos negativos por parte dos trabalhadores em relação a este assunto, tais como jornadas de trabalho que tendem a se estender além dos horários tradicionais.

Segundo reportagem da revista Época (2013), empresas como Yahoo e Best Buy, que utilizaram o home office por muitos anos, optaram por revogar esta prática devido a seu prejuízo nos anos anteriores, além da aparente falta de compromisso dos funcionários. Seus executivos acreditam que sua abolição permitirá produzir mais com menos trabalhadores.

Diante deste contexto, surgiu o interesse em pesquisar o home office, suas vantagens e desvantagens a partir da percepção dos trabalhadores. Para isso, foi pesquisada uma empresa multinacional de $\mathrm{Tl}$, chamada neste texto pelo nome fictício de SistEmp. A partir dos aspectos levantados na revisão bibliográfica, foi elaborado um questionário e um roteiro de entrevista sobre a experiência com o home office. 0 questionário foi respondido por 52 funcionários, sendo que 15

deles também foram entrevistados. A escolha dos participantes procurou diversificar o perfil das pessoas quanto à idade, gênero, tempo de empresa, estado civil, número de filhos, cidade onde reside e se trabalha ou não em home office.

Também foi realizada uma observação dos funcionários na empresa e foi realizada uma entrevista com um diretor da área de vendas que trabalha na empresa há mais de 15 anos, para compreender a visão da gerência sobre essa forma de trabalho. Antes de apresentar os resultados da pesquisa, apresenta-se a revisão bibliográfica sobre o tema.

\section{TECNOLOGIA DA INFORMAÇÃO}

Segundo Kenn (1993), a TI envolve o processamento de dados, os sistemas de informação e a engenharia de software e de hardware. A TI tem sido fator de aceleração do crescimento das principais economias globais. Isso é de fácil percepção ao se analisar aspectos que acompanham seu amadurecimento, como a geração de empregos, o crescimento geral da produtividade, a elevação dos índices de competitividades, entre outros. 
O uso da TI no ambiente empresarial tem sido considerado de grande importância, tanto no plano estratégico, quanto operacional. Seu uso é bastante difundido no ambiente de trabalho das empresas em diferente países e traz consigo os desafios da identificação de sua contribuição no resultado e na produtividade (ALBERTIN, 2005).

Embora a tecnologia vise facilitar a vida de quem a utiliza, existem certas resistências por parte de algumas pessoas em virtude da dificuldade de adaptação. Isso faz com que, muitas vezes, haja uma subutilização dos investimentos feitos em melhorias de bases tecnológicas instaladas nas empresas, ou seja, apesar dos gastos para melhorar o cenário, as soluções implementadas muitas vezes são subutilizadas por não serem bem aceitas por seus usuários (DIAS, 2000).

Em pesquisa realizada por Dias (2000) com gerentes de 43 empresas do Brasil, concluiu-se que existem três principais motivos para o uso de tecnologia da informação: utilidade, facilidade de uso e prazer. Os gerentes entrevistados pelo autor afirmaram que usam tecnologia principalmente porque acreditam que ela aumenta a qualidade de seu trabalho, agiliza a execução de tarefas e melhora sua produtividade.

De acordo com Turner (1998), a TI não se limita a modificar processos e a produtividade da empresa, mas tem papel fundamental na transformação da organização como um todo. Dentre as inúmeras modificações na organização, o avanço do uso da tecnologia da informação facilita formas de flexibilização das relações de trabalho (BARROS, SILVA, 2010). Existe um fenômeno do ambiente empresarial que se tornou possível com a difusão da $\mathrm{TI}$, o chamado teletrabalho ou home office. Segundo Morgan (2004), metade da população ativa mundial irá trabalhar neste formato até 2050 . Neste modelo, se enquadra qualquer forma de trabalho por meio de tecnologia da informação e comunicação fora do escritório da organização (TREMBLAY, 2002).

No Brasil, a indústria de TI se consolidou na década de 1970 e tem acompanhado o crescimento do país, proporcionando soluções para variados segmentos de mercado. $O$ mercado de TI brasileiro é um dos mais aquecidos do mundo e um dos setores que mais gera empregos no país. O ramo é responsável por empregar 160 mil pessoas e os salários apresentaram crescimento acima da inflação nos anos 2000 (ABRADISTI, 2013; BUBLITZ, 2013).

\section{TRABALHO FLEXÍVEL E HOME OFFICE}

O conceito de trabalho flexível pode assumir diferentes conotações, relacionado ao local, horário ou contrato. No home office, observa-se pelo menos as duas primeiras formas de flexibilidade (MORGAN, 2004). É uma forma de trabalhar por meio de $\mathrm{TI}$, em que pelo menos parte das atividades é desenvolvida fora da organização (MARTíNEZ-SÁNCHEZ et al., 2007; TREMBLAY, 2002).

A difusão da telefonia móvel e da internet, os problemas de deslocamento nas grandes cidades e a necessidade de estar em contato com os clientes acabaram por tornar interessante essa forma de trabalho. Um dos motivos pelo qual as empresas incentivam o home office é a possibilidade de diminuir custos com instalações físicas e outros gastos com os funcionários (IKEDA, 2013). 
Existem muitos benefícios do home office para os trabalhadores, tais como menor necessidade de deslocamento, maior liberdade e flexibilidade, melhor ambiente de trabalho, menores distrações e custos, liberdade com as vestimentas, fuga do jogo político do escritório e facilidade para gerir as tarefas domésticas (MANN et al., 2000). No entanto, também existem efeitos negativos já, tais como jornadas de trabalho que tendem a ser maiores que a jornada tradicional de oito horas, maior risco de perda de identidade e maior dificuldade de construção de carreira (SILVA, 2008; TIETZE, 2005).

Os teletrabalhadores tendem a ficar mais satisfeitos quando possuem menor dependência de outras pessoas da equipe. Quando o número de horas dedicadas ao trabalho começa a se estender além do usual, o trabalhador tende a ficar insatisfeito (GOLDEN; VEIGA, 2005). Mann, Varey e Button (2000) pesquisaram as vantagens e desvantagens percebidas nas vidas pessoal e profissional. Dentre as vantagens citadas, dastacaram-se:

Menor necessidade de deslocamento;

Maior liberdade e flexibilidade;

Melhor ambiente de trabalho;

Menores distrações;

Menos custos;

Liberdade com as vestimentas;

Fuga do jogo político do escritório e facilidade para gerir as tarefas domésticas.

Entre as desvatagens citadas pelos trabalhadores pesquisados por Mann, Varey e Button (2000), as principais foram:

a) Isolamento;

b) Aumento da jornada de trabalho;

c) Falta de suporte e ajuda pessoal;

d) Impossibilidade de abstenção por motivo de doença;

e) Dificuldade de progresso na carreira;

f) Aumento nos custos para os trabalhadores.

O custo aparece tanto como vantagem, quanto como desvantagem. A razão que o coloca como benéfico é o indivíduo não necessitar de transporte para o local de trabalho. Como desvantagem, o aumento com gastos de energia, investimentos em infraestrutura e materiais. Isso se estende para a falta de suporte relacionado a recursos tecnólogicos, pois se os instrumentos de TI falham em casa, não há quem resolva (MANN, VAREY e BUTTON, 2000).

Os autores atribuem a dificuldade de crescimento na carreira à falta de visibilidade e, também, à pouca experiência dos gestores para avaliar o desempenho dos teletrabalhadores. Por se tratar de uma modalidade de trabalho relativamente nova, os supervisores são despreparados e, além disso, as metas das pessoas que trabalham de casa são frequentemente maiores (MARTINEZSANCHES et al., 2007; TREMBLAY, 2002). 
Com relação à infraestrutura física, muitas pessoas sentem a necessidade de adequar a casa a um ambiente semelhante ao da empresa (FULTON, 2002). Cabe apontar que no escritório tradicional de algumas empresas, as mesas fixas de funcionários em vários departamentos foram extintas, porque ficavam vazias boa parte do expediente, quando seus funcionários estavam em visitas a clientes (IKEDA, 2013).

O esforço para planejar a divisão entre casa e trabalho pode levar os indivíduos a adotarem mecanismos que estabelecem essas fronteiras como, por exemplo, códigos de vestimenta e locais da casa destinados somente ao trabalho (TIETZE, 2002).

A seguir, analisa-se a percepção dos funcionários da SistEmp, na qual a prática de home office é muito usada.

\section{O HOME OFFICE NA SISTEMP}

A SistEmp é uma empresa de TI de origem norte-americana que, desde sua fundação vem aumentando sua participação no mercado e crescendo por meio de diversificação e aquisição de outras empresas. Atua nas áreas de hardware, software, banco de dados, aplicativos e suporte. A pesquisa foi realizada na unidade brasileira, localizada na cidade de São Paulo.

Os funcionários diretamente ligados à área de vendas não possuem horário fixo e também podem fazer home office quando julgarem necessário. Os gestores possuem controle apenas sobre suas metas e podem restringir a prática de home office se acharem melhor. O primeiro autor deste texto realizou estágio na empresa e poderia trabalhar de casa então, entretanto avaliava que isso não seria bom para um profissional em formação, por avaliar que o contato interpessoal seria importante para seu desenvolvimento naquela etapa da carreira.

A difusão da telefonia móvel e da internet, os problemas de deslocamento nas grandes cidades e a necessidade de estar em contato com os clientes acabaram por tornar interessante uma forma flexível de trabalho, fugindo do expediente tradicional, com um local de trabalho fixo.

O diretor entrevistado acredita que o home office tenha se difundido por ser vantajoso tanto para as corporações, quanto para seus funcionários, como mostra o trecho da entrevista a seguir:

Empresas que possuem uma grande operação de relacionamento direto com o cliente dificilmente têm a capacidade de seu escritório totalmente ocupada. As pessoas estão grande parte do tempo nos clientes. [...] Um escritório com espaços vazios aumenta o custo da empresa. [...] 0 incentivo ao home office talvez tenha surgido de uma necessidade de ambas partes.

As unidades das SistEmp normalmente se localizam em grandes centros urbanos, pois é onde estão seus principais clientes, o que justifica a prática do home office. Desde que se instalou no Brasil, nos anos 1980, a empresa cresceu 
muito. Suas instalações físicas tentaram acompanhar este crescimento, porém sempre de maneira defasada. O entrevistado comentou que, em 2012,

adquirimos um prédio de doze andares para ser a sede da SistEmp em São Paulo, entretanto, se todos os funcionários decidirem vir para o escritório ao mesmo tempo não haverá estação de trabalho para todo mundo. O espaço já foi concebido pensando na rotatividade das pessoas que estão em clientes e de home office.

Segundo disse, 30\% do tempo de trabalho dos funcionários da SistEmp é em suas casas. Essa prática facilita que pessoas trabalhem para a empresa, mas residam em outras cidades. Segundo o entrevistado, em sua equipe de doze pessoas, quase metade vive fora da capital. É o caso de dois respondentes, um que mora em Campinas e outro em Niterói. Apesar disso, o diretor entrevistado avalia que muitas pessoas ainda precisem se habituar com o home office:

Embora visualizem as vantagens que o home office poderia trazer para suas vidas, percebo que algumas pessoas não se sentem confortáveis em fazê-lo. Talvez seja uma questão cultural do brasileiro, que associa o trabalho efetivo ao tempo em que deve ficar no escritório. Em empresas como a SistEmp, o que conta como eficácia são os resultados. Apenas estar no escritório no horário de expediente não garante que a pessoa seja um bom funcionário.

O perfil dos respondentes pode ser visto na Tabela 1. A proporção de mulheres da amostra é próxima à da empresa como um todo, onde é de $25 \%$.

Tabela 1 - Perfil dos participantes

\begin{tabular}{ccc}
\hline & Total & Casados \\
\hline Homens & 40 & 15 \\
Mulheres & 12 & 4 \\
Total & 52 & 19 \\
\hline
\end{tabular}

Fonte: Pesquisa (2017)

Embora seja uma prática permitida pela empresa, a decisão de fazer home office é do próprio funcionário e de sua gerência, que é responsável por definir se tal prática é compatível para sua equipe. Entre os 52 respondentes, 33 fazem home office ( 25 homens e 8 mulheres). Os motivos apresentados por aqueles que não fazem são listados na Tabela 2.

Tabela 2 - Motivos para não fazer home office

\begin{tabular}{lc}
\hline \multicolumn{1}{c}{ Motivos } & Número de Respostas \\
\hline Gerência não permite & 13 \\
Falta de ambiente propício & 5 \\
Falta de equipamentos & 3 \\
Total & 21 \\
\hline
\end{tabular}

Fonte: Pesquisa (2017)

A maior parte atribui essa decisão ao fato de não ser permitido ou bem visto pela gerência. A área de apoio a vendas e a de inside sales (vendas internas) por telefone são as que têm mais restrições da gerência, ainda que existam gerentes 
dessas áreas que permitem home office. Quando questionada a respeito, uma entrevistada de vendas internas respondeu:

Quando cheguei na empresa, já fui avisada pelo gerente que na nossa vertical não se poderia trabalhar de casa. [...] Somos uma área de inside sales e, por isso, temos baia fixa de trabalho. [...] Com todos aqui, fica mais fácil para o gestor organizar e as atividades e avaliar cada um.

O Gráfico 1 apresenta a frequência com os respondentes trabalham "de casa", como costumam falar na SistEmp. Observa-se que cerca de um terço dos respondentes raramente se utiliza do home office, ou seja, menos de uma vez por semana. Apenas seis participantes trabalham somente de casa (11\%).

Gráfico 1 - Frequência do home office

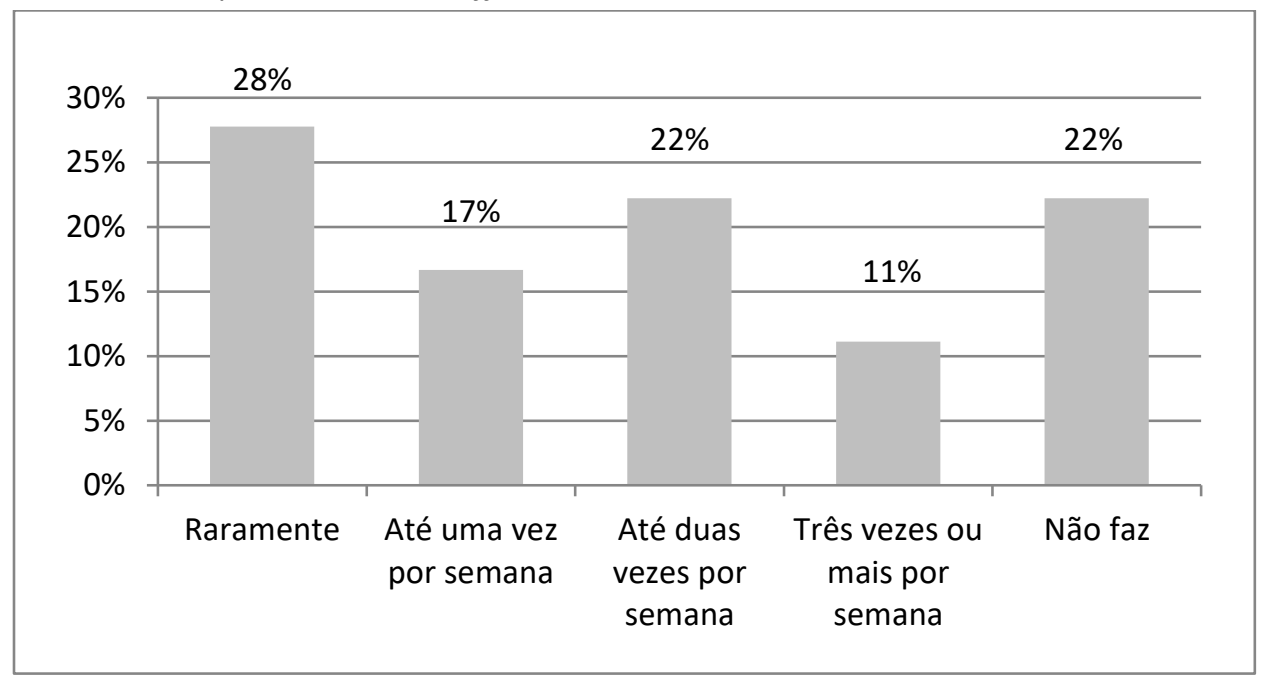

Fonte: Pesquisa (2017)

Houve divergência na porcentagem das pessoas que afirmou não trabalhar de casa (21) em relação a essa questão (15 no total), o que se deve a pessoas que respoderam negativamente a questão anterior, mas que responderam "raramente" nesta questão por considerarem que a frequência com que o fazem não caracteriza a adesão a essa prática. Existem funcionários que preferem trabalhar na empresa, mas mesmo assim reconhecem as vantagens de ter essa opção, como apontado por um entrevistado:

Sou do tipo que gosta de estar no escritório, mas considero o home office uma boa alternativa. Acho válido podermos usar [...] Geralmente, fico do home office uma vez na semana [...] Na maioria das vezes, escolho o dia do rodízio do carro, pois é mais prático ficar em casa do que sair muito cedo e voltar muito tarde.

A maioria (83\%) das pessoas avalia que sua produtividade é maior no home office, como mostra o Gráfico 2. 0 entrevistado que reside em Niterói disse que:

Com certeza sou mais produtivo de home office. [...] Meus filhos vão pra escola e minha esposa, para o trabalho, e só 
voltam no fim da tarde. Ir pra São Paulo ou pra filial do Rio de Janeiro me faz perder tempo no trajeto e o cansaço cumulativo afeta o trabalho como um todo com o passar dos dias.

A produtividade, no entanto, depende de outros fatores, como o hábito de trabalhar de casa, as outras pessoas que residem na casa e o espaço de trabalho. Um entrevistado que normalmente trabalha na empresa ressaltou a dificuldade que teve em um período em que trabalhou em casa:

Costumo trabalhar de casa raramente, mas, há cerca de um mês, lesionei o braço e recebi licença de duas semanas. Entretanto, tinha muitos projetos em andamento e duas semanas sem trabalhar comprometeriam meus resultados. Por isso, fiquei de home office nesses dias [...] O que posso afirmar é que pra quem não tem costume, a produtividade vai diminuindo ao longo do tempo. Quanto mais ficava em casa, menos eu trabalhava.

Gráfico 2 - Produtividade no home office

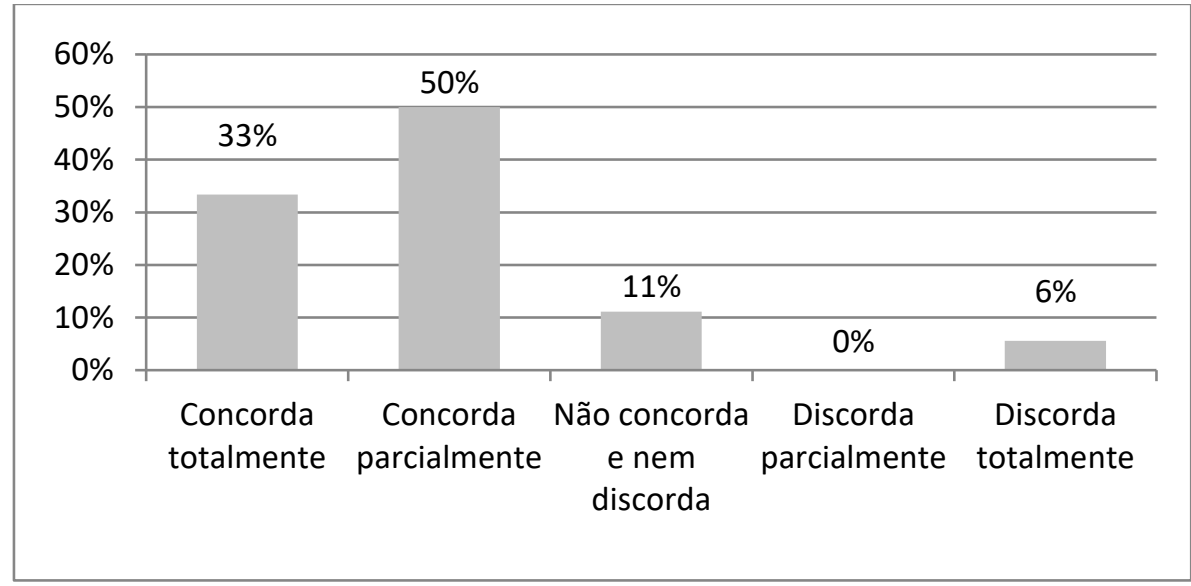

Fonte: Pesquisa (2017)

É interessante observar, no entanto, que este funcionário usou o home office como uma alternativa à licença por motivo de saúde, período durante o qual ele não iria trabalhar. Outro aspecto apontado na literatura é que o trabalho em casa tem menos distração. 0 Gráfico 3 apresenta a opinião dos funcionários a esse respeito. 
Gráfico 3 - Ambiente de trabalho em casa tem menos distração

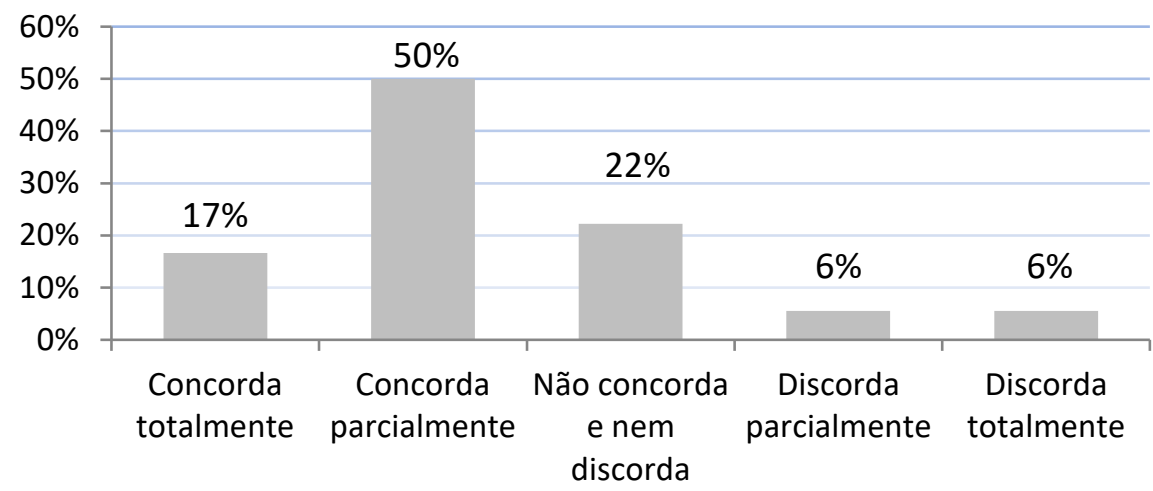

Fonte: Pesquisa (2017)

Havia uma expectativa de que televisão, videogame, vizinhos e animais domésticos seriam considerados distrações mais frequentes do que observado na empresa, mas $67 \%$ dos respondentes apontaram que existem mais distrações no escritório.

A área de pré-vendas da SistEmp é a que mais faz uso de home office e os respondentes apontaram as distrações do ambiente do escritório como o principal motivo para isso: pessoas que interrompem as atividades, ruídos, ensaios de apresentações, entre outros. Um entrevistado dessa área comentou que:

Em casa consigo ficar mais concentrado. [...] Por ser de uma área técnica, acabo tendo mais conhecimento sobre os produtos da empresa e os vendedores me procuram a toda hora para pedir ajuda. Porém, apoiar os vendedores é uma das muitas atividades do pré-vendas. [...] Quando fico no escritório, muitas vezes acabo fazendo só isso,

em prejuízo das demais atividades que ele tem que realizar. A literatura aponta, ainda, uma série de outros aspectos vantajosos do home office. A Tabela 3 apresenta o quanto os respondentes concordam com esses aspectos.

Tabela 3 - Vantagens do home office

\begin{tabular}{|c|c|c|c|c|c|}
\hline Aspectos vantajosos & $\begin{array}{c}\text { Muito } \\
\text { pouco } \\
\text { vantajoso }\end{array}$ & $\begin{array}{c}\text { Pouco } \\
\text { vantajoso }\end{array}$ & Neutro & Vantajoso & $\begin{array}{c}\text { Muito } \\
\text { vantajoso }\end{array}$ \\
\hline Não precisa se deslocar & - & - & - & 9 & 37 \\
\hline Liberdade & - & - & 13 & 6 & 26 \\
\hline Flexibilidade & - & - & 4 & 13 & 29 \\
\hline $\begin{array}{ll}\text { Liberdade } & \text { com } \\
\text { vestimentas } & \end{array}$ & - & 6 & 3 & 3 & 33 \\
\hline Custos & 2 & 5 & 5 & 9 & \\
\hline $\begin{array}{l}\text { Gestão de tarefas } \\
\text { domésticas }\end{array}$ & - & 3 & 30 & 5 & 8 \\
\hline Jogo político do escritório & 10 & 3 & 18 & 5 & 10 \\
\hline
\end{tabular}

Fonte: Pesquisa (2017) 
Observa-se que os respondentes concordam com a maior parte das vantagens apontadas pela literatura. A possibilidade de trabalhar sem ter que se deslocar ao local trabalho distante é uma das vantagens mais facilmente perceptíveis do home office. A fala de um entrevistado ilustra o quanto o deslocamento pode ser prejudicial numa cidade grande:

Minha vertical não permite que ninguém faça home office, então, não tenho escolha a não ser pegar o fretado todos os dias [...] e voltar. Cada trajeto dura cerca de uma hora e meia. No final do dia, são três horas que considero improdutivas.

A liberdade também foi considerada bem vantajosa pelos respondentes. Entretanto, 13 consideram esse aspecto neutro. Um dos motivos para isso pode ser o fato de a SistEmp ser uma empresa bem liberal, como sugere a fala de um entrevistado:

a SistEmp permite que se use o telefone e a internet para resolver questões pessoais. Podemos inclusive acessar redes sociais do escritório. A única liberdade que tenho a mais em casa é poder usar qualquer roupa e escutar música alta, mas não considero isso necessariamente uma vantagem.

Outra questão explorada foi a flexibilidade, ou seja, o fato de a pessoa poder se desligar do trabalho para tratar de assuntos pessoais ou familiares. Pode-se observar que 29 pessoas consideram a flexibilidade muito vantajosa no trabalho em casa. Por meio das entrevistas, porém, percebeu-se que muitas pessoas consideram flexibilidade e liberdade fatores sobrepostos, talvez por isso o consolidado da questão que tratava da flexibilidade ficou bem parecido com o anterior, liberdade.

A maioria considera a liberdade na forma de ser vestir, porém, algumas pessoas apontaram para o aspecto como pouco vantajoso. Ao ser questionado sobre isso, um funcionário disse:

Poderia ficar de pijama o dia todo, mas isso seria depressivo. Sempre procuro colocar algo um pouco menos confortável.

O jogo político do escritório relaciona-se a situações nas quais as pessoas precisam controlar seu mau humor ou trabalhar com outros funcionários cuja presença nem sempre é bem vinda por exemplo. As pessoas ficaram bem divididas em relação a essa questão, sendo que a maioria é neutra. Um entrevistado que considera esse aspecto vantajoso comentou como

O jogo político é uma questão bem estressante do trabalho aqui na empresa. O pessoal de vendas recebe uma forte cobrança todos os dias. [...] Já vi, muitas vezes, pessoas sendo reprimidas de maneira inadequada e que não respondem a altura por estar um nível abaixo na hierarquia.

Outro entrevistado, no entanto, aponta como

As relações interpessoais do escritório são imprescindíveis para quem quer se desenvolver na área comercial. [...] As situações mais tensas e de resolução de conflitos são as que 
mais agregam nesse aspecto. Trabalhar de casa somente pra fugir disso não é uma boa ideia.

Esse entrevistado já toca em um dos aspectos apontados como desvantajoso na literatura, relacionado ao crescimento na carreira. A opinião sobre este aspecto, assim como outros aspectos apontados como desvantagens é apresentada na Tabela 4. Percebe-se que a maioria concorda com a dificuldade de crescimento na carreira no home office. Um dos entrevistados que frequentemente faz home office disse que seu gestor o alertou que as coisas na SistEmp "não acontecem para quem só trabalha de casa", dando a entender que, para ser lembrado numa possível promoção, a pessoa tem que estar a vista.

Tabela 4 - Desvantagens do home office

\begin{tabular}{lccccc}
\hline Aspectos desvantajosos & $\begin{array}{c}\text { Muito } \\
\text { desvan- } \\
\text { tajoso }\end{array}$ & $\begin{array}{c}\text { Desvan- } \\
\text { tajoso }\end{array}$ & Neutro & $\begin{array}{c}\text { Pouco } \\
\text { desvan- } \\
\text { tajoso }\end{array}$ & $\begin{array}{c}\text { Muito pouco } \\
\text { desvan- } \\
\text { tajoso }\end{array}$ \\
\hline Dificuldade na carreira & 18 & 10 & 10 & 3 & 5 \\
Isolamento & 22 & 2 & 13 & - & 2 \\
Falta de ajuda & 9 & 16 & 16 & - & - \\
Jornada de trabalho & 22 & 2 & 13 & - & 2 \\
Licença saúde & 4 & 4 & 24 & 2 & 4 \\
\hline
\end{tabular}

Fonte: Pesquisa (2017)

O isolamento dos colegas de trabalho foi considerado desvantajoso por grande parte das pessoas e uma boa parte permaneceu neutra em relação a este aspecto. As entrevistas apontaram que a principal desvantagem do isolamento é a dificuldade de conseguir ajuda nas atividades, o que é mais uma desvantagem em si, também apresentada na tabela. Um entrevistado da área de vendas explica o porquê dessa dificuldade:

Existem muitos processos internos da empresa, como geração de contratos, aprovação de formas de pagamentos não tradicionais, assuntos que envolvem o jurídico [...] que devem ser resolvidos rapidamente para que não emperre a venda. Para isso, os vendedores têm que estar perto das pessoas que podem ajudar. Além disso, temos muitos produtos com diferentes funcionalidades para vender. Por isso, é sempre bom ter um especialista por perto para tirar dúvidas.

Outro aspecto abordado pela literatura a respeito do home office é a perda de controle da jornada de trabalho, pois as pessoas acabam por dedicar o dia todo ao trabalho e deixam de lado as demais atividades. A maioria dos respondentes concorda. $\mathrm{O}$ trecho a seguir ilustra como o entrevistado se sente a respeito:

quando estamos no escritório e vamos pra casa, [...] existe um ponto de transição que avisa o subconsciente que acabou o trabalho naquele dia. É claro que sempre há e-mail chegando no celular e se a gente for ler todos, só vai acabar o trabalho na hora de dormir.

Outro entrevistado disse: 
Muitas vezes eu perco a noção do tempo trabalhando de casa. Fico concentrado nas coisas que estou fazendo e quando me dou conta já é quase meia noite. [...] Faço home office a maior parte do tempo, então, preciso me policiar pra conciliar o trabalho e a vida pessoal.

O último aspecto abordado na pesquisa foi a impossibilidade das pessoas que fazem home office faltarem ao trabalho por motivo de doença. Este tema foi abordado na literatura, porém os resultados da pesquisa mostraram que esta não é um preocupação dos funcionários da SistEmp. Segundo os entrevistados, pela cultura da empresa, não é preciso atestado médico para poder faltar ao trabalho, ela só deve avisar o gestor. Caso precise de um tempo maior, é sugerido que se faça home office sempre que possível.

Pode-se observar uma divisão dos respondentes em dois grupos, que se apresentam em fases distintas da vida: um deles é formado por pessoas casadas e com filhos; outro é formado por jovens solteiros, recém ingressos no mercado de trabalho e que têm como objetivo a ascensão rápida na carreira e o acúmulo de riqueza. O primeiro grupo vê mais vantagens no home office, enquanto o segundo, embora consiga visualizar as vantagens desse modelo, não possui vivência e maturidade para aproveitá-lo mais.

\section{CONCLUSÃO}

Pode-se observar claramente na pesquisa com funcionários da empresa pesquisada que, como proposto na literatura, são muitas as vantagens do home office, tais como menores custos, maior produtividade, maior conforto e liberdade, entre outros. Também foi possível observar que existem efeitos negativos, como a perda de controle da jornada de trabalho e o isolamento.

Houve alguns aspectos em relação aos quais a opinião dos respondentes divergiu em relação ao apontado pela literatura. Mann, Varey e Button (2000) destacaram a fuga do jogo político da empresa e a facilidade de gestão das tarefas domésticas, mas, para o contexto da empresa pesquisada, estas não mostraram muita influência na opção de trabalhar em casa. Muitas pessoas consideram que a sobreposição de atividades domésticas e trabalho mais atrapalha do que ajuda.

Outro aspecto que foi confirmado é o uso do home office em substituição à licença por motivos de saúde, o que reforça o aspecto de intensificação do trabalho que se soma ao aumento da jornada. Este é um aspecto interessante para ser mais pesquisado, assim como os casos de empresas que implantaram o home office, mas estão voltando atrás, a percepção de gerentes sobre não terem os funcionários próximos todos os dias e estudos quantitativos comparando a produtividade dos funcionários na empresa e em casa. 


\title{
Home office at multinational company of Information Technology
}

\begin{abstract}
This paper analyzes the work at home office, its advantages and disadvantages considering the workers' perception. For this purpose, a research was carried out at a multinational company of information technology (IT) and information was collected by a questionnaire answered by 52 employees, interviews with 15 of these respondents, observation of these when they went to the company, and an interview with a director of the sales area. The employees' perception confirms many of the advantages highlighted in the literature, such as lower costs, higher productivity, greater comfort and freedom, among others. It was also possible to confirm negative aspects, such as longer working days and the isolation. There were divergences in relation to the literature related to the advantage of running away from the company's political game and the facility to perform household tasks.
\end{abstract}

KEYWORDS: Work organization. Telework. Home-office. Information technology. 


\section{REFERÊNCIAS}

ABRADISTI. ABRADISTI realiza evento para apresentação oficial da associação ao mercado brasileiro, 2013. <www.abradisti.org.br>

ALBERTIN, A. L. Benefício do uso de tecnologia de informação no desempenho empresarial. FGV-EAESP/GVPESQUISA, n. 7, 2005.

BARROS, A. M. SILVA, J. R. G. Percepções dos indivíduos sobre as consequências do teletrabalho na configuração home-office: estudo de caso na Shell Brasil. Cadernos EBAPE, v. 8, n.1, 2010, p.72-91.

BUBLITZ, J. Como a falta de mão de obra em TI impacta o setor, 2013.

$<$ <ww.abradisti.org.br>

DIAS, D. S. Motivação e Resistência ao Uso da Tecnologia da Informação: um Estudo entre Gerentes. RAC, v. 4, n. 2, 2000, p. 51-66. crossref

ÉPOCA. Após Yahoo!, Best Buy também acaba com home office. Revista Época, 06/03/2013.

FULTON, C. Information control in the virtual office: preparing intermediaries to facilitate information exchange in the home work environment. New Library World, v.103, n.6, 2002, p. 209-215. crossref

IKEDA, P. A vez dos sem-mesa, da Stiefel à Unilever. Revista Exame, 10/08/2013.

KANTER R. M. Work pray love. Harvard Business Review. December 2010, p.38.

KEEN, P.G.W. Information Technology And The Management Theory: The Fusion Map. IBM Systems Journal, v.32, n.1, 1993, p.17-38. crossref

MANN, S.; VAREY, R.; BUTTON, W. An exploration of the emotional impact of teleworking via computer-mediated communication. Journal of Managerial Psychology, v.15, n.7, 2000, p. 668-690. crossref

MARTíNEZ-SÁNCHEZ, A., PÉREZ-PÉREZ, M., DE-LUIS-CARNICER, P.; VELA-JIMÉNEZ, M. J. Telework, human resource flexibility and firm performance. New Technology, Work and Employment, v.22, n.3, 2007, p.208-223. crossref 
MORGAN, R. Teleworking: an assessment of the benefits and challenges.

European Business Review, v.16, n.4, 2004, p.344-357. crossref

SILVA, J. R. G. Profissionais qualificados e experiência de autoemprego: questões de tempo e espaço. Read, v.14, n.1, 2008, p. 214-239.

TIETZE, S. Discourse as strategic coping resource: managing the interface between "home" and "work". Journal of Organization Change Management, v.18, n.1, 2005, p.48-62. crossref

TREMBLAY, D. Balancing work and family with telework? Organizational issues and challenges for women and managers. Women in Management Review, v.17, n.3-4, 2002, p. 157-170. crossref

TURNER, J. A. The role of information technology in organizational transformation. New York, John Wiley \& Sons, 1998.

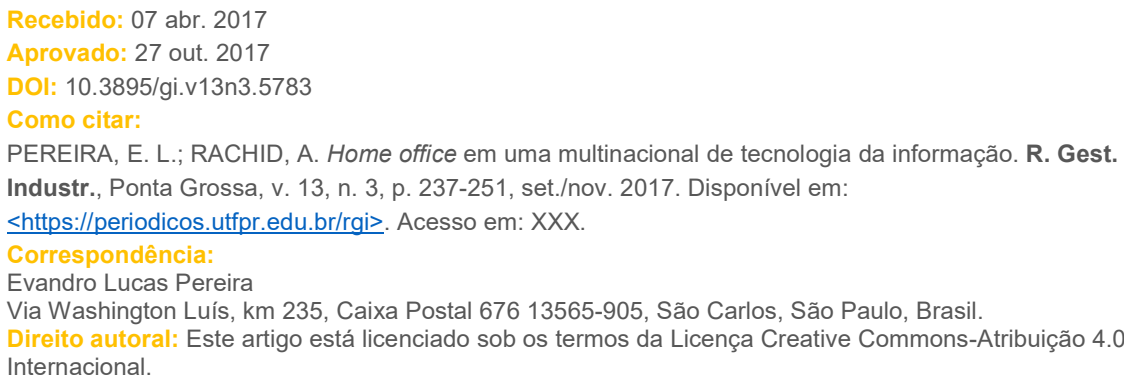

Via Washington Luís, km 235, Caixa Postal 676 13565-905, São Carlos, São Paulo, Brasil.

\section{(c) (i)}

